\title{
How Can We Statistically Analyze the Achievement of Diagrammatic Competency from High School Regular Tests?
}

\author{
Yuri Uesaka ${ }^{1(\bowtie)}$, Shun $\mathrm{Saso}^{1}$, and Takeshi Akisawa ${ }^{2}$ \\ ${ }^{1}$ Graduate School of Education, The University of Tokyo, Tokyo, Japan \\ yuri.uesaka@ct.u-tokyo.ac.jp \\ 2 Tsurumine Senior High School, Chigasaki, Kanagawa, Japan
}

\begin{abstract}
Owing to the recent global changes in education goals, students nowadays need to achieve 'key competencies' in school. 'Diagrammatic competency' is an essential part of such competencies. To cultivate diagrammatic competency, it is necessary to evaluate teachers and students and provide feedback on the students' degree of achieving diagrammatic competency. Regular school tests can provide useful opportunities for assessing such achievement. However, in such tests, Japanese high schools mainly focus on evaluating the understanding of learning contents rather than the development of competencies (such as diagrammatic competency). The current study was a collaboration between educational psychologists and a high school mathematics teacher. Together they modified a regular school test to incorporate tasks that require diagrammatic competency to solve them, thus enabling the assessment of such achievement. The study was conducted in an actual high school. The students' performance was analyzed using cognitive diagnostic models [1], which statistically estimate how well students have mastered the elements of cognitive abilities and skills required to solve problems, generating 'attribute mastery probabilities'. The attribute mastery probabilities obtained demonstrated that students' achievement of diagrammatic competency was insufficient, indicating a need for cultivating such competency in subject learning instruction provided in schools.
\end{abstract}

\section{Necessity of Assessing Diagrammatic Competency in School}

Although traditional school instruction emphasizes the acquisition of the contents of various subjects, due to the recent global changes in educational goals, developing students' learning competencies are now increasingly considered an essential objective of school education. This perspective is embodied in the idea of 'key competencies' proposed by the Organization for Economic Cooperation and Development (OECD). The ability to use external resources, such as diagrams, has been considered one of the most critical among those key competencies.

An essential aspect that needs to be cultivated in school is using diagrams effectively, which can be referred to as 'diagrammatic competency'. For example, Kragten et al. [2] emphasized that "diagrammatic literacy" is vital in secondary science education. Furthermore, based on findings about the efficacy of self-constructed diagrams 
(e.g., [3]), the ability to construct diagrams has also been integrated into the concept of diagrammatic competency.

To cultivate diagrammatic competency, it is necessary to evaluate and provide feedback to students and teachers on the students' extent of achieving it. Regular school tests can provide valuable opportunities for assessing such achievement. However, such tests in Japanese high schools mainly focus on evaluating the understanding of learning contents rather than the development of competencies like diagrammatic competency. Thus, this study proposes a framework that can evaluate diagrammatic competency in school students statistically, with the use of regular school tests.

In this study, the students' performance was analyzed using cognitive diagnostic models (CDMs) [1]. As described later in more detail, this analysis assumes that students can solve problems if they master the elements of cognitive abilities and the skills required for problem-solving (i.e., 'attributes'), and it estimates how well students have mastered attributes (i.e., 'attribute mastery probabilities'). The current study incorporated diagrammatic competency into the analysis as one of the attributes and attempted to statistically calculate how students master diagrammatic competency using CDMs.

\section{Development of Tasks to Assess Diagrammatic Competency}

Educational psychologists and a high-school mathematics teacher collaborated for this study; they worked together to modify a regular school test to incorporate tasks requiring diagrammatic competency to solve problems.

The problems assessing diagrammatic competency essentially were of two types: the first ones were tasks that were also included in the traditional regular test; however, it could also assess the diagrammatic competency (e.g., item 1 in Fig. 1). The second type required diagrammatic competency for problem-solving, which was newly incorporated in this regular test (e.g., item 2 in Fig. 1). As reflected by these problems, the current study defined diagrammatic competency operationally as the ability to imagine a necessary diagrammatic representation when solving a given problem. The regular test was conducted in an actual high school, and 40 students took the test.

In this study, the attributes representing diagrammatic competency along with four other attributes were identified. In addition to 'diagrammatic competency (A1)', 'comprehension of math terminology (A2)', 'application of a mathematical formula (A3)', 'understanding relations between numerical expressions (A4)', and 'computational skills (A5)' were incorporated as attributes in this study.

To conduct the analysis of CDMs, it was necessary to specify the item-attribute relationship in the form of a matrix, called a 'Q-matrix'. The Q-matrix for this study was specified by the math teacher and two educational psychologists. Inter-rater agreement between the math teacher and one of the educational psychologists was confirmed as substantially equivalent (Cohen's $\kappa=.66$, 95\% confidence interval, .54.78). Inconsistencies in the Q-matrix were discussed between the two educational psychologists.

An example of the Q-matrix for the tasks in Fig. 1 is presented in Table 1. It indicates, for instance, that to solve item 1 in Fig. 1, other attributes such as 'A4', 'A5' are necessary, together with diagrammatic competency (A1). A total of 40 students took the regular test that was administered. 


\begin{tabular}{|c|c|c|}
\hline & Item 1 & Item 2 \\
\hline Task & $\begin{array}{l}\text { Let } \mathrm{D} \text { be the domain represented by the } \\
\text { three inequalities } y-x \leq 0, y+2 x \geq \\
0,2 x-y-4 \leq 0 \text {. Find the maximum } \\
\text { and minimum values of } x+y \text { when } \\
\text { point }(x, y) \text { moves within this domain. }\end{array}$ & $\begin{array}{l}\text { Let } C \text { be a parabola } y=f(x) \text { and } \\
\text { take a point } P\left(a, 2 a^{2}\right) \text { on } C \text {, where } \\
a>0 \text {. Let the tangent at the } P \text { on } C \text { be } l \text {. } \\
\text { Let point } Q \text { be the intersection of line } \\
l \text { and the } x \text {-axis, line } m \text { be perpendicular } \\
\text { to } l \text { through } Q \text {, and point } A \text { be the } \\
\text { intersection of } m \text { and the } y \text {-axis. Choose } \\
\text { one of the following (1) to (4) as the } \\
\text { most appropriate representation of } \\
T=\int_{0}^{a}\left\{2 x^{2}-\left(4 a x-2 a^{2}\right)\right\} d x \\
(1) \text { Area of the square } O Q P A \\
\text { (2) Area of the figure bounded by } \\
\text { curve } C \text { and line } l \\
\text { (3) Area of the figure enclosed by } \\
\text { curve } C \text {, line } l \text {, and } y \text {-axis } \\
\text { (4) Area of the figure enclosed by } \\
\text { curve } C \text {, line } l \text {, and the } x \text {-axis }\end{array}$ \\
\hline $\begin{array}{l}\text { Nec- } \\
\text { essary } \\
\text { Dia- } \\
\text { gram }\end{array}$ & $y=2 x-4$ & $\left.\right|^{y=2 x^{2}}$ \\
\hline & \%(min & $\begin{array}{c}a \\
y=4 a x-2 a^{2}\end{array}$ \\
\hline
\end{tabular}

Fig. 1. Example tasks assessing diagrammatic competency

Table 1. Example of Q-matrix

\begin{tabular}{cccccc} 
Attribute & $\begin{array}{c}\text { Al:Diagrammatic } \\
\text { Competency }\end{array}$ & $\begin{array}{c}\text { A2:Comprehension of } \\
\text { Math Terminology }\end{array}$ & $\begin{array}{c}\text { A3:Application of } \\
\text { a Mathematical Formula }\end{array}$ & $\begin{array}{c}\text { A4:Understanding Relations } \\
\text { between Numerical Expressions }\end{array}$ & $\begin{array}{c}\text { A5:Computational } \\
\text { Skills }\end{array}$ \\
\hline \hline Item1 & 1 & 0 & 0 & 1 & 1 \\
\hline
\end{tabular}

\section{Results and Discussion}

In the current study, DINA (the deterministic inputs, noisy “and" gate) model was applied for analysis. The R2jags package in the R program was used with five chains, 30,000 
iterations, and 10,000 burn-in. All the model parameters were confirmed to converge. Attribute mastery probabilities for each student were calculated. Table 2 shows examples of outputs. It also illustrates that the analysis with CDMs makes it possible to empirically demonstrate unique patterns of students' acquisition of each attribute and their acquisition of diagrammatic competency.

Following previous studies, in the current study, 0.5 was used to decide whether students were judged as mastering the attribute. The result of the analysis revealed the percentages of students who mastered each attribute: acquisition of 'diagrammatic competency' was $52.5 \%$, 'comprehension of math terminology' was $52.5 \%$, 'application of a mathematical formula' was $67.5 \%$, 'understanding relations between numerical expressions' was $45.0 \%$, and 'computational skills' was $60.0 \%$. This suggests that almost half of the students in a class did not sufficiently master diagrammatic competency.

Table 2. Example of output: attribute mastery probabilities (excerpt)

\begin{tabular}{cccccc}
\hline Student ID & $\begin{array}{c}\text { A1:Diagrammatic } \\
\text { Competency }\end{array}$ & $\begin{array}{c}\text { A2:Comprehension of } \\
\text { Math Terminology }\end{array}$ & $\begin{array}{c}\text { A3:Application of } \\
\text { a Mathematical Formula }\end{array}$ & $\begin{array}{c}\text { A4:Understanding Relations } \\
\text { between Numerical Expressions }\end{array}$ & $\begin{array}{c}\text { A5:Computational } \\
\text { Skills }\end{array}$ \\
\hline \hline 1 & 0.19 & 0.55 & 0.90 & 0.54 & 0.80 \\
17 & 0.97 & 0.90 & 1.00 & 0.05 & 0.99 \\
23 & 0.09 & 0.89 & 0.93 & 0.31 & 0.92 \\
37 & 0.44 & 0.83 & 0.71 & 0.59 & 0.60 \\
\hline
\end{tabular}

In this study, cluster analysis was conducted to categorise the students into several groups. Four clusters were obtained, as listed in Table 3. The students belonging to the two larger clusters did not achieve diagrammatic competency. The results indicate the necessity of cultivating diagrammatic competency in school practices.

Table 3. Results of cluster analysis (ward's method) of students

\begin{tabular}{ccccccc}
\hline Cluster ID & $N$ & $\begin{array}{c}\text { A1:Diagrammatic } \\
\text { Competency }\end{array}$ & $\begin{array}{c}\text { A2:Comprehension of } \\
\text { Math Terminology }\end{array}$ & $\begin{array}{c}\text { A3:Application of } \\
\text { a Mathematical Formula }\end{array}$ & $\begin{array}{c}\text { A4:Understanding } \\
\text { Relation between } \\
\text { Numerical Expressions }\end{array}$ & $\begin{array}{c}\text { A5:Computational } \\
\text { Skills }\end{array}$ \\
\hline \hline 1 & 12 & 0.30 & 0.62 & 0.87 & 0.59 & 0.79 \\
2 & 17 & 0.46 & 0.41 & 0.31 & 0.46 & 0.41 \\
3 & 8 & 0.92 & 0.64 & 1.00 & 0.85 & 0.99 \\
4 & 3 & 0.98 & 0.93 & 1.00 & 0.03 & 1.00 \\
\hline
\end{tabular}

\section{References}

1. Rupp, A.A., Templin, J., Henson, R.A.: Diagnostic Measurement: Theory. Methods and Applications. Guilford Press, New York (2010)

2. Kragten, M., Admiraal, W., Rijlaarsdam, G.: Diagrammatic literacy in secondary science education. Res. Sci. Educ. 43, 1785-1800 (2012)

3. Ainsworth, S., Prain, V., Tytler, R.: Drawing to learn in science. Science 26, 1096-1097 (2011) 
Open Access This chapter is licensed under the terms of the Creative Commons Attribution 4.0 International License (http://creativecommons.org/licenses/by/4.0/), which permits use, sharing, adaptation, distribution and reproduction in any medium or format, as long as you give appropriate credit to the original author(s) and the source, provide a link to the Creative Commons license and indicate if changes were made.

The images or other third party material in this chapter are included in the chapter's Creative Commons license, unless indicated otherwise in a credit line to the material. If material is not included in the chapter's Creative Commons license and your intended use is not permitted by statutory regulation or exceeds the permitted use, you will need to obtain permission directly from the copyright holder.

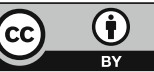

